\title{
AN ACTIVE CARING APPROACH THROUGH PSYCHOLOGICAL SAFETY IN CONSTRUCTION PROJECTS
}

\author{
Sulyn Gomez ${ }^{1}$, Bryan Bishop², Glenn Ballard ${ }^{3}$, Mario Saenz ${ }^{4}$, and Iris \\ Tommelein 5
}

\begin{abstract}
Guided by the lean principle of respect for people, it is key to recognize the value of construction workers feeling psychologically safe on site. Psychological safety is proven to be a driver for learning behaviors as it allows workers feel confident about asking questions to get clarity on their work, asking for help, or speaking up when errors occur on site to avoid repeating mistakes. The authors framed the understanding of psychological safety in the context of a construction project and analyzed worker's perception regarding factors that foster a psychologically safe work environment. In this study, different trades shared their perception about factors that made them feel safe or unsafe while working at the job site. Outcomes highlighted human behavior characteristics such as how the willingness of workers to speak up when they see someone doing something unsafe changed depending on whom they are talking to. Results were analyzed with the project's leadership team and action items were set in place. Changes implemented included using English and Spanish during weekly meetings and the establishment of an on-site safety committee to strength relations between and amongst different trades as well as discussion with foremen to keep growing psychological safety on site.
\end{abstract}

\section{KEYWORDS}

Psychological safety, behavior, active caring, learning, safe, sustainable change.

\section{INTRODUCTION}

Since the concept of psychological safety was introduced, many researchers have analyzed its correlation and outcomes in different industries such as healthcare (Kessel et al. 2012; Turner and Harder 2018), manufacturing (Lee et al. 2011 and Edmondson 1999), technology (Bergmann and Schaeppi 2016), etc. However, the applicability of the concept in the construction industry is still an on-going development. Howell et al. (2017) showed the relationship between the lean principle "respect for people" and psychological safety. In parallel, many studies have been developed to predict safety

1 PhD Student, Civil and Environmental Engineering Department, University of California, Berkeley, CA 94720-1712, USA, +1 765 775-6583, sulyn@ berkeley.edu

2 Safety Manager, Webcor Builders, CA 94107, USA, +1 510 612-5019, bbishop@ webcor.com

3 Research Director, Civil and Envir. Engrg. Dept., Project Production Systems Lab., Univ. of California, Berkeley, CA 94720-1712, USA, +1 415 710-5531, gballard@ berkeley.edu

4 Project Engineer, Webcor Builders, CA 94107, USA, +1 510 502-6185, msaenz@ webcor.com

5 Professor, Civil and Envir. Engrg. Dept., Director of the Project Production Systems Lab., Univ. of California, Berkeley, CA 94720-1712, USA, +1 510 643-8678, tommelein@ berkeley.edu 
outcomes on construction projects considering factors such as safety risks of trades or tasks (Esmaeili and Hallowell 2013), attribute-based risks (Esmaeili et al. 2015), and number of employees (Camino Lopez et al. 2008; Hinze and Gambatese 2003). Nevertheless, apart from Howell et al. (2017), little consideration has been given to psychological safety. Some efforts that partially overlap with psychological safety have been done to analyze safety from the psychological side such as behavior-based safety (Lin et al. 2015; Choudhry 2014) and safety climate (Newaz et al. 2018; Fang et al. 2006; Hon et al. 2014; Mohamed 2002; Glendon and Litherland 2001; Johnson 2007). However, in isolation those prediction models do not seem to be a sustainable solution since rates for safety incidents do not reflect a significant improvement. Even though the predicted correlations may be there, failure to improve safety performance may have resulted from not adequately acting on the driving factors. According to the Bureau of Labor Statistics (BLS 2018), more than $20 \%$ of worker fatalities in private industry in 2017 were in construction. In response to the need to find a sustainable solution that deals with upstream behaviors, we referred to Newman et al. (2017) who expanded on the benefits that psychological safety brings to organizations in different levels, the situations in which it is most influential, and the factors that may lead to its development. Kahn (1990 p.708) defined psychological safety as "feeling able to show and employ one's self without fear of negative consequences to self-image, status, or career," which means that in a safe work environment, individuals can be comfortable being themselves and they will not be afraid to admit an error because they expect to receive help, not harm from confessing. Later, Edmondson (1999 p.350) defined psychological safety as "a shared belief that the team is safe for interpersonal risk-taking" with the expectation that individuals will mutually respect each other and not get embarrassed, rejected or punished for speaking up. Nembhard and Edmondson (2006) suggested that when individuals feel psychologically safe, they speak up freely and are not constrained by others' disapproval or negative responses. For this study, psychological safety can be seen as a mood, and like all moods, it is based on assessments of the future. When grounded (e.g., construction workers hide errors because they fear punishment, ranging from being fired to being made fun of), the only way to change their mood is to remove the reason for their fear. They might be afraid because that is what has happened on previous projects, in which case demonstrating that speaking up does not bring punishment can change their mood of psychological safety. Studies have documented the usefulness of constructing a psychological safe environment that is a necessary foundation for trust and for establishing a learning culture. Particularly in hazardous situations, psychological safety is critical because people speak more freely about their concerns, provide feedback on the processes they are executing, and reduce potential errors (Newman et al. 2017).

Psychological safety greatly influences people's behavior, consequently, a lack of psychological safety can cause people to feel intimidated or reluctant to ask for help or be unwilling to raise concerns or ask questions for fear of a sanction (Edmondson 1999). Common fears from workers tend to be related to damaging their reputation or putting at risk any potential promotions or raises (Edmondson 1999). Some of the same fears are shared by construction workers. The authors found common factors that help workers feel safe or unsafe in the field. Behaviorally, psychological safety allows workers to raise their concerns, ask for help, and increase their sense of belonging on a team (Pearsall and Ellis 2011). In construction, field workers directly add value to the 
process at the front-end of operations; therefore, creating a psychological safe work environment where they can actively participate asking questions or giving suggestions during operations design fosters ownership of their work and increases the sense of responsibility for the outcomes. To improve project performance, Wu et al. (2017), Hardison et al. (2014) and Stiles et al. (2018) identified some practices that generate leadership behaviors such as individualized consideration, inspirational motivation, innovative changes and meeting employees' emotional appeal to improve site safety. Edmondson (1999) stated that a psychologically safe environment can be fostered by a supportive coaching-oriented leader. Leaders can co-create an environment under certain conditions that modify team beliefs and therefore team behaviors in the pursuit of increasing team performance. Also, Hardison et al. (2014) listed other practices that build leadership behaviors for site supervisors such as establishing effective communication and positive leader-member exchanges. Some of these practices were used to implement changes and foster psychological safety in the project site studied.

\section{RESEARCH DESIGN}

As the authors were actively engaged in the research group and the effort to build psychological safety in the project under study, the paper is written as the first intervention of a larger action research cycle. Somekh (2005) suggested action research as a proper research method for a study that involves successive actions in a cycle of testing and improving. Similarly, Lewin (1946) emphasized the fact that action research allows practitioners to test if certain action result in improvements. The authors intervened and documented a project specific case where the project team aimed to build psychological safety for field workers through the implementation of certain actions.

The plan of each iteration in the action research process includes: i) an initial assessment of the current state, ii) discussion on action items to mitigate any deviation from what is described as a psychologically safe environment, and iii) testing whether such intervention brings the desired outcomes and adjusting the plan as needed for another intervention. First, the first author conducted observations on site that involved attending site orientations for new employees, daily safety meetings, coordination meetings, and all hands weekly meetings. Second, the authors designed and administered an extensive questionnaire to obtain quantitative and qualitative information from the workers regarding the current state of psychological safety in the project. Third, a discussion session with the project leaders and the research team was developed to decide on action items based on outcomes from the observations, the administered survey, and conversations with workers in the field. The research also investigates the different beliefs or perspectives from workers on a construction site regarding their role and their supervisor's role in creating a safe site. The authors reduced risks of social reactivity such as the Hawthorne Effect that suggests that causal factors can be caused for the fact of being studied (Colman 2015) by explaining the field workers and their leaders the reasoning behind the study and the benefits expected from their collaboration. A level of trust among the researchers and the study participants was established through continuous interaction on the field. Survey findings indicated substantial room for improvement in certain areas which supported by suggestions from experienced people in the field gave the study the level of accuracy needed to create a baseline which will be used in later studies. 


\section{Project Description}

The project under study is a 12-story concrete building with a structural steel penthouse and a total area of 359,703 square foot. This building will be the Center for Neurovision Science Building of the University of California, San Francisco - Mission Bay Campus. Webcor Builders is the general contractor in the project, leading the effort to foster psychological safety. At the time this study was documented, the phases of the project under construction were superstructure build out and interior rough in.

\section{Data Collection}

The instrument used for data collection was a survey distributed to 100 craft workers. No personal information about respondents was included in records. There was a response rate of $64 \%$ to the first survey. $25 \%$ of the responses were from the general contractor self-perform work groups and $75 \%$ were from the subcontractors' workers.

\section{Procedure}

The survey questionnaires were distributed and collected personally by the first author. There was a series of one-on-one conversations with each worker to make sure they understood the study purpose and to make them feel safe to answer questions truthfully.

Data collection lasted for over two weeks, and the respondents completed the surveys during regular working hours. The questionnaire included 18 questions $\mathrm{s}^{\mathrm{i}}$, some of the statements asked the participants whether they agreed with each statement and to what degree, while others were open-ended questions such as "what makes you feel safe or unsafe on site?" Statements graded by participants had a 7-point Likert-type scale $(1=$ strongly disagree, $7=$ strongly agree $)$. Among the questions, reverse-scored questions were included to verify that workers were reading the questions carefully and answering the survey honestly. A reverse question example is "If I make a mistake, my co-workers do/do not teach me how to avoid making that same mistake again."

\section{Participants}

Workers from different trades participated in the study. Table 1 summarizes the number of participants who submitted their responses per trade.

Table 1: Study Participants per Trade

\begin{tabular}{cccc}
\hline Trade & $\begin{array}{c}\text { Number of } \\
\text { Participants }\end{array}$ & Trade & $\begin{array}{c}\text { Number of } \\
\text { Participants }\end{array}$ \\
\hline Carpenter & 9 & Iron Worker & 4 \\
Labor & 9 & Water Proofing & 4 \\
Drywall & 12 & Plumbing & 9 \\
Roofing & 6 & Electrical & 6 \\
Fire Sprinkler & 3 & NA: Not specified & 2 \\
\hline
\end{tabular}

\section{RESEARCH FINDINGS AND DISCUSSION}

\section{Caring About Each Other - An Active Approach}

It tends to be an intrinsic belief that people speak up whenever they see someone in dangerous conditions and prevent potential accidents on site. However, the study results 
show that there are certain conditions in which people are more willing to speak up than in others. One of the statements included in the questionnaire stated: "If I see someone on my crew doing something unsafe, I speak up." 43 of the 64 respondents said they Strongly Agree with this statement, but only 24 did so when asked if they would speak up "If I see someone on another crew doing something unsafe, I speak up." Fewer were willing to warn people from other trades even though they might be as much at risk of injury. Also, two other statements were related to showing an active approach on site (see Table 2). Both statements positively show that craft workers in the project tend to feel that they have the support of their co-workers from the same crew to correct work and they are also satisfied with the commitment to work safely on the project site.

Table 2: Statements Related to Caring About Each Other and Participant's Answers

\begin{tabular}{llllllll}
\hline Statement & Rate (1: Strongly Disagree / 7: Strongly Agree) \\
\hline $\begin{array}{c}\text { unsafe, I speak up } \\
\text { If I see someone on my crew doing something }\end{array}$ & $\mathbf{1}$ & $\mathbf{2}$ & $\mathbf{3}$ & $\mathbf{4}$ & $\mathbf{5}$ & $\mathbf{6}$ & $\mathbf{7}$ \\
\hline $\begin{array}{c}\text { unsafe, I speak up } \\
\text { If see someone on another crew doing something }\end{array}$ & 1 & 0 & 0 & 0 & 5 & 16 & 43 \\
$\begin{array}{c}\text { If I make a mistake, my co-workers in the crew } \\
\text { help me learn how to do the work correctly }\end{array}$ & 0 & 2 & 0 & 2 & 3 & 31 & 25 \\
$\begin{array}{c}\text { I am satisfied that there really is a commitment to } \\
\text { a safe work environment where I am now working. }\end{array}$ & 0 & 0 & 0 & 0 & 4 & 25 & 33 \\
\hline
\end{tabular}

\section{SUPERVISORS: ROLE MODEL FOR SAFETY}

In the study, questions about whether workers' supervisors acting as a role model who commits to safety have an average rating of 6.0 point between the 4 statements (Table 3 ), meaning that leaders are overall trying to create a safe culture in the project through role modeling, which resonates with the field observations from the first author.

Table 3: Statements Related to the Worker's Perception About Supervisors

\begin{tabular}{llllllll}
\hline \multicolumn{1}{c}{ Statement } & Rate (1: Strongly Disagree / 7: Strongly Agree) \\
\hline $\begin{array}{c}\text { My direct supervisor is a good role model for } \\
\text { safety }\end{array}$ & 1 & $\mathbf{2}$ & $\mathbf{3}$ & $\mathbf{4}$ & $\mathbf{5}$ & $\mathbf{6}$ & $\mathbf{7}$ \\
\hline $\begin{array}{c}\text { My direct supervisor is understanding and helpful } \\
\text { when I make a mistake at work }\end{array}$ & 3 & 1 & 1 & 0 & 8 & 32 & 19 \\
$\begin{array}{c}\text { My direct supervisor is willing to listen to my ideas } \\
\text { for improving how work is done }\end{array}$ & 0 & 3 & 1 & 4 & 8 & 27 & 21 \\
$\begin{array}{c}\text { I feel comfortable talking to my direct supervisor } \\
\text { about my safety concerns at work }\end{array}$ & 0 & 2 & 0 & 0 & 10 & 22 & 30 \\
\hline
\end{tabular}

However, it is worth noting that the first two statements in Table 3 have a few lowrated responses, e.g. five participants indicating that they Strongly Disagree or Disagree with "My direct supervisor is understanding and helpful when I make a mistake at work." 
Results suggest that an area for improvement for the team is working towards building confidence that supervisors are a useful and helpful resource for facilitating information, solutions, and help when problems arise. For instance, previous studies have shown such correlation, e.g. Edmondson (1999) and Roberto (2002) analyzed the role of the team leader in supporting and coaching the employees to build a safe work environment. Also, Grill and Nielsen (2019) found that site managers see their function as role models for behaviors of field workers at the sites and Hardison et al. (2014) analyzed the safety competencies that are most important for construction supervisor leadership.

\section{Creating a Safe Environment - Expected Behaviors in House}

To improve psychological safety on site, the research team and the leaders of the project discussed action items that were to be implemented on site based on the survey outcomes and observations on the field.

\section{Foster or Increase Safe Conditions and Behaviors}

To get a better understanding of the different factors affecting field workers comfort and sense of confidence, a couple of open-ended question were included in the survey. The first question asked "What make you feel safe on site?" and the second one asked "What would help you feel safe to speak up - to raise concerns, to ask questions, to feel confident that if you make a mistake, you get help, not punishment." Responses varied as people's motivations differ from each other. For example, for the second open-ended question, a worker from one crew said, "getting a signed paper that says I won't be fired for making a mistake"; however, another worker explained for the first open-ended questions that "seeing a clean place whenever I move to another zone" would make him feel safe. Responses for both open-ended questions were categorized in common groups such as communication, safety manager, clean place, etc. To facilitate visualization of the different responses, the authors used a word clouds (see Fig. 1 for open-ended questions 1 "What make you feel safe on site?") to show which factors had more impact than others by analyzing which answers were more repetitive in participants' responses.

\section{SafetyManager}

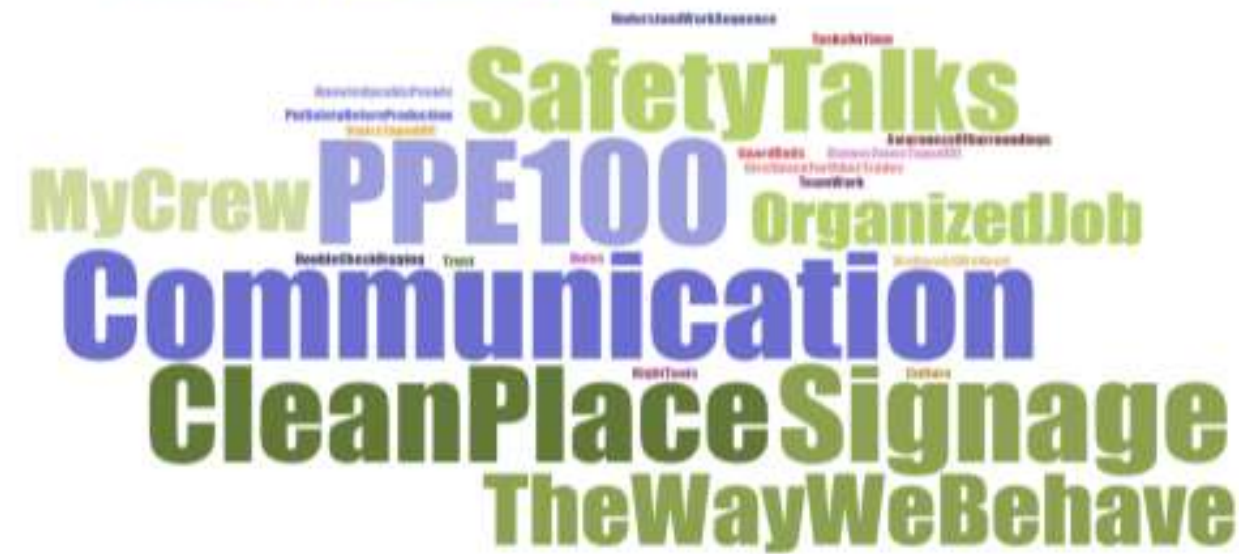

Figure 1: Word Cloud with Factors That Make Workers Feel Safe

Based on this analysis, some ideas were discussed with the project team and later implemented on site to foster a psychologically safe work environment for craft workers: 
- Errors as Opportunities for Learning not to Fear: Carmeli and Gittell (2009) suggested that when individuals feel respected and confident that they will not be blamed, ridiculed, or punished, people are more likely to speak up, admit errors, look for help and learn. Employees' personal beliefs grounded in psychological safety help workers to have better communication among each other and admit errors without fear (Newman et al. 2017). On site, there was an effort to let the workers know that no one is perfect and free of mistakes, but each member of the team was expected to commit with continuous improvement and their feedback was needed to do a better and safer job as a team. Also, the project team rewarded workers to speak up with a practical campaign of giving free lunches to workers who showed learning behaviors by sharing their ideas, concerns or requests either with their supervisors or submitting them to the suggestions box located in the field. Also, the project implemented a "Doing it Right" campaign in which it recognizes workers for their behaviors, sharing ideas, concerns, or requests. This is directly supported by day to day conversations, having suggestion boxes on the job, and sharing team's information such as cell phone numbers on their hardhats so every worker can reach out for help, suggestions or requests to improve the site.

- Focus on Learning Behaviors: A psychologically safe workplace allows innovation to occur, and it provides opportunities to learn from others' errors and to correct and address common mistakes (Guchait et al. 2014). Another statement included in the questionnaire was "I'm always learning new skills working with this crew," the average rating was 6.4 points with 31 respondents saying they Strongly Agree, which showed that there was a sense among workers that they were actually learning from their peers and it made them feel safe. Many authors suggested that psychological safety is linked to greater knowledge sharing (Newman et al. 2017; Siemsen et al. 2009). Also, Wilkens and London (2006), Liu et al. (2014), Ortega et al. (2010), and Roberto (2002) established positive links between psychological safety and learning behaviors. According to Edmondson (1999), learning behaviors include seeking feedback, sharing information, asking for help, talking about errors, and experimenting. On this project, the team has tried to overcome the problem of reoccurring mistakes that put workers in hazardous situations by implementing a near miss reporting tool. The reporting and sharing of near misses have helped the workers feel free to speak up and has given everyone a chance to learn from others. Near misses are discussed during plan of the day meetings, posted in the workers' lunch area, and shared across the company to bring awareness of dangerous conditions or behaviors. Similarly, with the spirit of knowledge sharing, the team captured key examples that were developed in the project using prevention through design methods and share them as success stories with the workers in order to encourage knowledge sharing and innovation. Such examples were included in the on-boarding presentation that the safety manager of the project uses during introductions to the project. The team pursued to create a project learning environment where operations are designed for a safe execution.

- Increasing Familiarity Among Groups: Sanna and Shotland (1990) described the direct impact of audience or other work groups in the performance of an individual and Edmondson (1999) suggested that by increasing the level of 
familiarity among teams we might potentially lower interpersonal threats and encourage people to ask for help, admit errors and discuss problems. Moreover, Roberto (2002) highlighted that prior interaction or familiarity among team members is a key driver of psychological safety. Some thoughts had been discussed in the project to encourage workers to get together such as integration events or gather together meetings. A couple of ideas that had been implemented after the survey was done are explained below in greater detail.

- English and Spanish in All Hands Weekly Meetings: In order to improve communication on site, the project team decided to use both languages to make sure that the messages were delivered in a way that all workers can understand expectations and instructions and feel free to communicate it in the same way. Given the high percentage of craft workers for whom Spanish is their first language, it was worth it to convey the most important messages to the field in both English and Spanish.

- An Active Safety Committee: To build psychological safety on site, the project team decided to create certain routines to systematically increase strength and cohesiveness on the team. Newman et al. (2017) suggested that psychological safety is more potent and meaningful at the team level. A safety committee was established as a grassroots-level organization led by a project engineer from the GC. The safety committee was composed of one member from each of the trades; with different level of experience, from apprentice to foreman. It serves as a community platform that strives to change the safety culture from within. Leadership, or a purposeful lack thereof, played a key role in the success of the committee. The committee's purpose was not to push a single agenda but to empower each committee member to look out for one another. The project engineer's role was to set up the meetings, identify the locations and area of focus, and start the conversation. The project team, followed the example of the Leader Standard Work that originated with Toyota, which includes routine activities intended to promote psychological safety and to develop learning behaviors - centered around periodic job walks between supervisor and supervised (Poksinska et al. 2013). Monthly safety walks and weekly check-ins were held with the committee. The purpose of the walks was to identify things that are going well, things that need to be improved, and a way to track progress from the previous months. Cross-pollination of trade's knowledge and experiences also played a key role in breaking barriers and frustrations within trades, and to develop trust with each member of the committee. Once trust was built within the committee, the team focused on building trust with the rest of the field crews. To do so the committee emphasized anonymous reporting and no repercussions on individuals who brought up issues. Once trust was built in the field, safety concerns started to surface that were not brought up before, giving the committee the opportunity to address the new concerns.

\section{Mitigate or Reduce Unsafe Conditions and Behaviors}

Argyris (1982) said that when people face the potential for threat or embarrassment, their learning is inhibited. In construction for example, site managers tend to suffer from time pressure which affects their behaviors and normal performance on site. The survey included another question to identify which factors make workers feel unsafe on 
site. Responses are summarized in a word cloud below (Fig. 2). Also, some means to mitigate factors making workers feel unsafe are discussed.

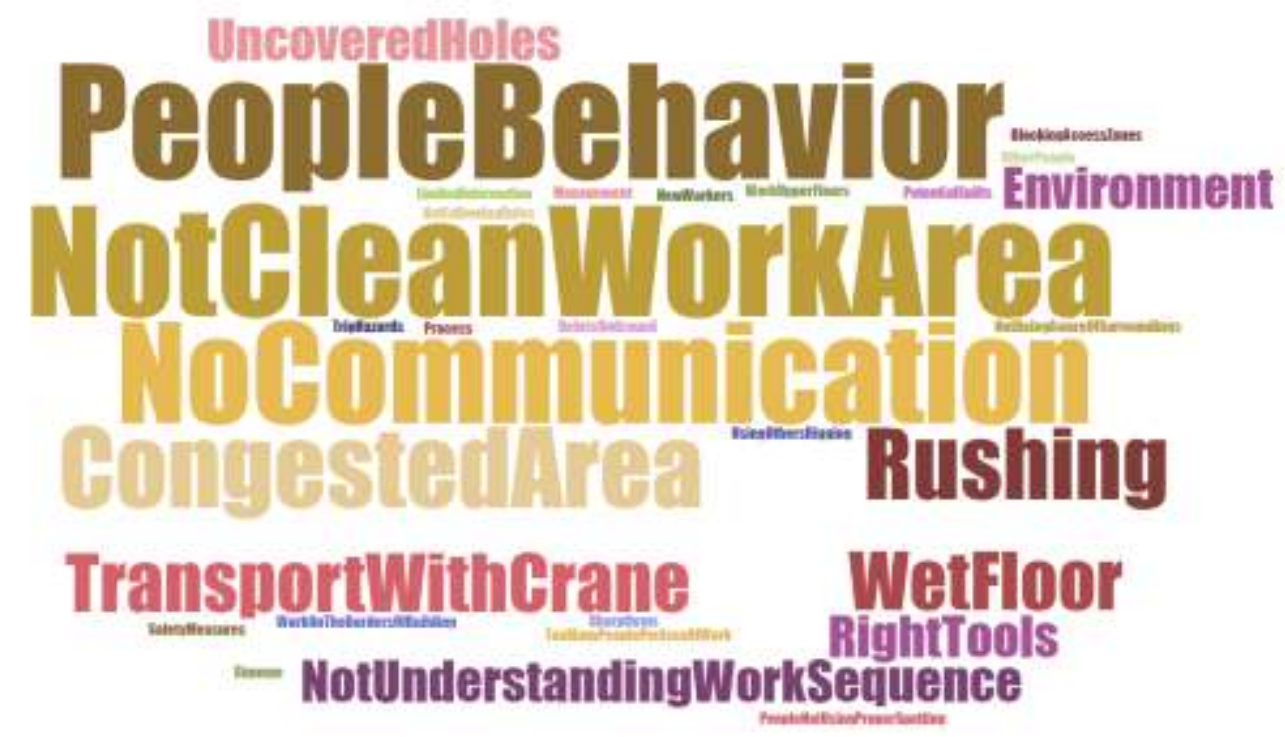

Figure 2: Word cloud With Factors That Make Workers Feel Unsafe

- People's Behavior - Errors as Opportunities for Learning not to Fear: Carmeli and Gittell (2009) highlighted that errors tend to provoke fear, but they are also a rich opportunity to learn. Edmondson (1999) also suggested that there are two conditions that compel workers to feel more motivated to speak up: i) if they believe they will not be rejected, and ii) the new uncovered information will be using to generate useful results. On site, there is a "Speak Up for Safety" initiative which can be seen around the project on banners in both English and Spanish. This initiative is carried by everyone on site and all levels of management are responsible to convey the message that workers can freely speak up about any concern and feel confident that they would get help.

- Be Respectful with Other's Space - Clean as You Go: The safety manager played a key role in delivering the message that maintaining a clean area is more productive and safer. During on-boarding for new workers, "Clean as you go" policy of the project is described as removing trash as work is being done and not at the end of the day. Expectations regarding cleanliness are clearly communicated to the workers as they come to the project.

- Improve Sharing Information and Communication: Increasing communication on site was suggested from the survey and the project team started sharing information in the plan of the day meetings to help crews to understand work flow. Also, as the project is being built around Lean, the principle of "respect for people" is applied in different scenarios. To improve communication for example, as the team recognized that not all workers are proficient in a language, the safety manager provides the option to workers to choose which language to use during orientations. Clear conversations increase the likelihood of making sure the messages are understood. This helped to show that the management team cares about their workers, but also improves understanding of work sequence, and thus avoided having congested areas. 


\section{CONCLUSIONS}

The study showed that there are common patterns that help construction workers to either feel more safe or unsafe working on site. Psychological safety has proven its potential to impact team performance, and factors affecting psychological safety on construction sites should be studied. Responses to the question seeking factors that make workers feel unsafe on site allow identifying areas where leaders need to focus. Moreover, providing the conditions that help workers feel safe on site is as important as mitigating the unsafe conditions. The way site managers and superintendents behave plays a key role in shaping craft workers' feelings and behaviors. It is the project leaders' responsibility to promote psychological safety and learning behaviors on teams. This necessary condition must be matched with consistent supervisory behavior down all chains of command. How "my" boss treats me trumps everything else.

If a project team is looking for their collaborators to feel free to speak up, a good alternative is sharing experiences in which mistakes did not lead to rejection but rather had the team engagement in solving an issue together showing true interest. By doing so, behaviors shift to a more active approach to create a psychologically safe work environment. The study provided empirical evidence that when a project prioritizes psychological safety, the workers recognize the change and feel free to give suggestions for further improvement. The findings also highlighted that actions taken to keep building psychological safety on site such as the content included in the personal orientations, the way issues are handled and addressed, the increase of interrelatedness by the creation of a safety committee as well as using both languages during weekly all hands meeting can highly positively impact the workers' perception about how much the company cares about them, and then they also started caring about each other in the same way. The study uncovered some of the workers' main concerns; for example, they cared a lot about other people's behavior and it helped the team directing efforts towards building upstream behaviors that are translated into an active care approach.

\section{LIMITATIONS}

The limited amount of samples do not allow for generalization in particular findings, but rather the authors aimed to set a baseline for future studies and convey the different thoughts and expectations from a sample project and shared some of the initiatives that the project team put in place and can be replicated in other projects.

\section{ACKNOWLEDGMENTS}

Development of the ideas presented in this paper was supported in part by gifts made to the Project Production Systems Laboratory (P2SL). All support is gratefully acknowledged. Any opinions, findings, conclusions, or recommendations expressed in this paper are those of the authors and do not necessarily reflect those of contributors to P2SL.

\section{REFERENCES}

Argyris, C. (1982). Action: Individual and Organizational. Auflage, San Francisco, London.

Bergmann, B., and Schaeppi, J. (2016). A Data-Driven Approach to Group Creativity. Harvard Business Review, 12. 
Bureau of Labor Statistics. (2018). "Census of Fatal Occupational Injuries 2017."

Camino L., M. A., Ritzel, D. O., Fontaneda, I., and Gonzalez Alcantara, O. J. (2008). Construction industry accidents in Spain. Jrnl. of Safety Research, 39, 497-507.

Carmeli, A., and Gittell, J. H. (2009). High-Quality Relationships, Psychological Safety, and Learning from Failures in Work Organizations. Jrnl. of Organizational Behavior: The Int'l Jrnl. of Industrial, Occupational and Organizational Psychology and Behavior, 30(6), 709-729.

Choudhry, R. M. (2014). Behavior-based Safety on Construction Sites: A Case Study. Accident analysis \& prevention, 70, 14-23.

Colman, A. M. (2015). A Dictionary of Psychology. Oxford Quick Reference.

Edmondson, A. C. (1999). Psychological Safety and Learning Behavior in Work Teams. Administrative Science Quarterly, 44(2), 350-383.

Esmaeili, B., and Hallowell, M. (2013). Integration of Safety Risk Data with Highway Construction Schedules. Construction Mgmt. and Economics, 31(6), 528-541.

Esmaeili, B., Hallowell, M. R., and Rajagopalan, B. (2015). Attribute-Based Safety Risk Assessment. II: Predicting Safety Outcomes Using Generalized Linear Models. Jrnl. of Construction Engineering and Mgmt., 141(8), 04015022.

Fang, D., Chen, Y., and Wong, L. (2006). Safety Climate in Construction Industry: A Case Study in Hong Kong Jrnl. of Construction Eng. and Mgmt., 132(6), 573-584.

Glendon, A. I., and Litherland, D. K. (2001). Safety Climate Factors, Group Differences and Safety Behavior in Road Construction. Safety Science, 39(3), 157-188.

Grill, M., and Nielsen, K. (2019). Promoting and Impeding Safety - A Qualitative Study into Direct and Indirect Safety Leadership Practices of Constructions Site Managers. Safety Science, 114, 148-159.

Guchait, P., Paşamehmetoğlu, A., and Dawson, M. (2014). Perceived Supervisor and Co-Worker Support for Error Management: Impact on Perceived Psychological Safety and Service Recovery Performance. Int'l. Jrnl. Hospitality Mgmt., 41, 28-37.

Hardison, D., Behm, M., Hallowell, M. R., and Fonooni, H. (2014). Identifying Construction Supervisor Competencies for Effective Site Safety. Saft. Sci.,65,45-53.

Hinze, J., and Gambatese, J. (2003). Factors that Influence Safety Performance of Specialty Contractors. Jrnl. of Construction Eng. and Mgmt., 129(2), 159-164.

Hon, C. K., Chan, A. P., and Yam, M. C. (2014). Relationships Between Safety Climate and Safety Performance of Building Repair, Maintenance, Minor Alteration, and Addition (RMAA) Works. Safety Science, 65, 10-19.

Howell, G., Ballard, G., \& Demirkesen, S. (2017). Why Lean Projects are Safer. In Proceedings of the 25th Annual Conference of the International Group for Lean Construction, Heraklion, Greece (pp. 4-12).

Johnson, S. E. (2007). The Predictive Validity of Safety Climate. Jrnl. of Safety Research, 38(5), 511-521.

Kahn, W. A. (1990). Psychological Conditions of Personal Engagement and Disengagement at Work. Academy of Management Jrnl., 33(4), 692-724.

Kessel, M., Kratzer, J., and Schultz, C. (2012). Psychological Safety, Knowledge Sharing, and Creative Performance in Healthcare Teams. Creativity and Innovation Management, 21(2), 147-157.

Lee, J. Y., Swink, M., and Pandejpong, T. (2011). The roles of worker expertise, Information Sharing Quality, and Psychological Safety in Manufacturing Process Innovation: An Intellectual Capital Perspective. Prod and Ops Mng, 20(4), 556-570. 
Lewin, K. (1946). Action Research and Minority Problems. Jrnl. of Social Issues, 2(4), 34-46.

Li, H., Lu, M., Hsu, S. C., Gray, M., \& Huang, T. (2015). Proactive behavior-based safety management for construction safety improvement. Safety sci., 75, 107-117.

Liu, S., Hu, J., Li, Y., Wang, Z., and Lin, X. (2014). Examining the Cross-Level Relationship Between Shared Leadership and Learning in Teams: Evidence from China. The Leadership Quarterly, 25(2), 282-295.

Mohamed, S. (2002). Safety Climate in Construction Site Environments. Jrnl. of Construction Engineering and Management, 128(5), 375-384.

Nembhard, I. M., and Edmondson, A. C. (2006). Making it Safe: The Effects of Leader Inclusiveness and Professional Status on Psychological Safety and Improvement Efforts in Health Care Teams. Jrnl. of Organizational Behavior: The Int'l. Jrnl. of Industrial, Occupational and Organizational Psych. and Behavior, 27(7), 941-966.

Newaz, M. T., Davis, P., Jefferies, M., and Pillay, M. (2018). Using a Psychological Contract of Safety to Predict Safety Climate on Construction Sites. Jrnl. of Safety Research, 68, 9-19.

Newman, A., Donohue, R., and Eva, N. (2017). Psychological Safety: A Systematic Review of the Literature. Human Resource Management Review, 27(3), 521-535.

Ortega, A., Sanchez-Manzanares, M., Gil, F., and Rico, R. (2010). Team Learning and Effectiveness in Virtual Project Teams: The Role of Beliefs About Interpersonal Context. The Spanish Jrnl. of Psychology, 13(1), 267-276.

Pearsall, M. J., and Ellis, A. P. J. (2011). Thick as Thieves: The Effects of Ethical Orientation and Psychological Safety on Unethical Team Behavior. Jrnl. of Applied Psychology, 96, 401-411.

Poksinska, B., Swartling, D. and Drotz, E., 2013. The daily work of Lean leaderslessons from manufacturing and healthcare. Total Quality Management \& Business Excellence, 24(7-8), pp.886-898.

Roberto, M. A. (2002). Lessons from Everest: The Interaction of Cognitive Bias, Psychological Safety, and System Complexity. Calif. Mgmt. Rev., 45(1), 136-158.

Sanna, L. J., and Shotland, R. L. (1990). Valence of Anticipated Evaluation and Social Facilitation. Jrnl. of Experimental Social Psychology, 26(1), 82-92.

Siemsen, E., Roth, A. V., Balasubramanian, S., and Anand, G. (2009). The Influence of Psychological Safety and Confidence in Knowledge on Employee Knowledge Sharing. Manufacturing and Service Operations Management, 11(3), 429-447.

Somekh, B. (2005). Action Research: A Methodology for Change and Development. McGraw-Hill Education (UK).

Stiles, S., Ryan, B., and Golightly, D. (2018). Evaluating Attitudes to Safety Leadership within Rail Construction Projects. Safety Science, 110, 134-144.

Turner, S., and Harder, N. (2018). Psychological Safe Environment: A Concept Analysis. Clinical Simulation in Nursing, 18, 47-55.

Wilkens, R., and London, M. (2006). Relationships Between Climate, Process, and Performance in Continuous Quality Improvement Groups. Jrnl. of Vocational Behavior, 69(3), 510-523.

Wu, C., Li, N., and Fang, D. (2017). Leadership Improvement and its Impact on Workplace Safety in Construction Projects: A Conceptual Model and Action Research. Int'l. Jrnl. of Project Management, 35(8), 1495-1511. 